\title{
EL PRINCIPIO DE DIGNIDAD EN LA JURISPRUDENCIA CONSTITUCIONAL MEXICANA *
}

\author{
Luis Eusebio Alberto AvendaÑo GonZález \\ Alina del Carmen NetTEl BARRERA \\ Jorge SerRano Ceballos \\ Profesores-investigadores de Derecho Constitucional Mexicano \\ Miembros del Sistema Nacional de Investigadores del CONACYT \\ Facultad de Derecho de la Universidad Autónoma de Querétaro \\ luis.avendano@botmail.com \\ alinanettel@botmail.com \\ licjorgeserrano@botmail.com
}

\begin{abstract}
RESUMEN
A partir de la reforma constitucional del 10 y 11 de junio de 2011 se constituyó el eje a partir del cual habría de ser modulado el concepto de los derechos bumanos y el Derecho en general. El principio de dignidad en su tratamiento filosófico, doctrinal y jurídico ba permitido modular lo que «dice el Derecho»o «debe decir el Derecho» como la herramienta racional en la aplicación del derecho «de los humanos». Así, la jurisprudencia constitucional mexicana describe en sus criterios el discurso a partir del cual reconoce la migración de la moral a los textos jurídicos positivos, lo que, en el caso mexicano, refleja que la función integradora de la Carta Magna opera también a partir de valores.
\end{abstract}

Palabras clave: principio de dignidad, jurisprudencia constitucional, derechos humanos, México.

\section{ABSTRACT}

The axe by which the concept of Human Rights and Law in general was to be ruled was set from the constitutional reform of 10/ 11 June 2011 onward. The principle of buman dignity, when treated philosophically, doctrinally and legally has let us adjust what is «According to the Law» or «According to what the Law should rule» as the rational tool to apply «The Law of Human Beings». Therefore, Mexican constitutional case law describes in its criteria the discourse by which it admits the moral's shift toward positive legal texts, which, in the case of

* El presente trabajo es producto parcial del proyecto de investigación denominado «Derechos humanos y las categorías sospechosas en el paradigma de la igualdad constitucional en México». 
Mexico, shows that the comprehending purpose of the Carta Magna works with values, too.

Keywords: The principle of human dignity, constitutional case law, human rights, Mexico.

\section{ZUSAMMENFASSUNG}

Im Anschluss an die Verfassungsreform vom 10. Und 11. Juni 2011, wurde die Leitlinie geschaffen, an der sich das Konzept der Menschenrechte und des Allgemeinen Rechts ausrichten sollten. Der Grundsatz der Menschenwürde in seiner philosophischen, lebrmässigen und juristischen Abhandlung hat es ermöglicht, «das, was das Gesetz sagt» oder «sagen sollte» anzupassen und wurde zum vernunftmäßigen Werkzeug bei der Anwendung des Rechts «der Menschen». Folglich beschreibt die mexikanische verfassungsrechtliche Rechtsprechung in ibren Kriterien den Diskurs, nach welchem sie die Einwanderung der Moral in die positiven Rechtstexte anerkennt. Dadurch wird deutlich, dass im Fall Mexikos die Magna Charta eine integrative Rolle wabrnimmt, die auch von den Werten ausgeht.

Schlüsselwörter: Der Grundsatz der Menschenwürde, Menschenrechte, Mexiko.

SUMARIO: I. INTRODUCCIÓN.-II. JURISPRUDENCIA IURIS.-1. La jurisprudencia constitucional mexicana y la contradicción de la tesis 293/2011. 2. El neoconstitucionalismo en la definición de la jurisprudencia nacional.-3. La moral en el Derecho constitucional.-4. Principios y normas. Un presupuesto necesario en la construcción del principio de dignidad.III. EL PRINCIPIO DE DIGNIDAD EN LA JURISPRUDENCIA CONSTITUCIONAL MEXICANA.-1. El derecho al mínimo vital en la jurisprudencia constitucional.-2. El concepto de dignidad en la jurisprudencia constitucional mexicana.-IV. CONCLUSIONES.-V. BIBLIOGRAFÍA.

\section{INTRODUCCIÓN}

El principio de dignidad humana constituye el eje a partir del cual se construyen todos los derechos humanos. A su vez, el término bioética ha pasado a formar parte del discurso jurídico en nuestro país. Uno y otro constituyen referentes que han dejado de ser simplemente filosóficos para tener un tratamiento cada vez más importante en la jurisprudencia constitucional mexicana.

A partir de ello cobra un nuevo sentido la Convención Americana sobre Derechos Humanos, que dispone en su art. 11, relativo a la protección de la honra y de la dignidad, lo siguiente: «a) Toda persona tiene derecho al respeto de su honra y al reconocimiento de su dignidad; $b$ ) nadie puede ser objeto de injerencias arbitrarias o abusivas en su vida privada, en la de su familia, en su domicilio o en su correspondencia, ni de ataques 
ilegales a su honra o reputación, y c) toda persona tiene derecho a la protección de la ley contra esas injerencias o esos ataques».

Además de lo anterior, la jurisprudencia mexicana se reconfiguró como consecuencia de la reforma constitucional de fecha 11 de junio de 2011, a partir de lo cual se creó un modelo más de integración jurisprudencial: a la reiteración y contradicción se sumó la sustitución. Para los efectos conducentes, el Acuerdo plenario 9/2011, de 9 de agosto de 2011, determinó la creación de la 10. ${ }^{a}$ época en materia de criterios jurisprudenciales, a la cual se ha identificado como «garantista». En este contexto, el objeto del presente ensayo consiste en identificar las posturas doctrinales y filosóficas en materia de dignidad y determinar su impacto en la jurisprudencia constitucional mexicana como parámetro de eficacia en la definición de los derechos humanos en nuestro país.

\section{JURISPRUDENCIA IURIS}

En palabras de Rolando Tamayo y Salmorán: «La jurisprudencia, al determinar lo que "dice el Derecho", constituye la herramienta indispensable para "calcular" las consecuencias en caso de aplicación del Derecho. La jurisprudencia es una herramienta de la razón práctica, de la prudentia: la prudentia iuris. La jurisprudencia es la ciencia de la aplicación del Derecho, la manera de razonar qué hacer en Derecho» ${ }^{1}$.

A partir de ello es posible predecir la sistematización de la razón jurídica, es decir, del pensamiento a partir del cual se construye el discurso científico en un tiempo y lugar determinado. Tal circunstancia en nuestro país se construye a partir de la determinación última que emite el poder judicial federal, la cual es clasificada por el propio poder público como histórica y vigente. Tal «verdad jurídica» en nuestro país cambió a consecuencia de las reformas constitucionales del 10 y 11 de junio de 2011.

\section{La jurisprudencia constitucional mexicana y la contradicción de tesis $293 / 2011$}

México, por virtud de las reformas constitucionales de fechas 10 y 11 de junio de 2011, no sólo incrementó su apartado de derechos humanos,

${ }^{1}$ R. Tamayo y Salmorán, Razonamiento y argumentación jurídica. El paradigma de la racionalidad y la ciencia del derecho, México DF, UNAM, 2014, p. 123.

Foro, Nueva época, vol. 19, núm. 1 (2016): 77-98 
sino que integró un catálogo de legislaciones y resoluciones extranjeras, lo cual supone hallarnos en presencia de un canon «internacionalista» donde el parámetro de validez remite no sólo al Derecho interno, sino también a las normas y criterios de interpretación emanados de sentencias, opiniones consultivas e informes de los organismos supranacionales.

Tal cambio de paradigma trajo consigo, por un lado, una serie de cambios sustantivos que inciden en la armonía entre el Derecho constitucional y el Derecho internacional de los derechos humanos, y que incluye, en virtud de la modificación del título I, capítulo I, del texto constitucional, el otorgamiento de rango constitucional a los tratados internacionales en materia de derechos humanos. Por otro lado, los cambios operativos permiten incidir procesalmente para hacer efectivos los derechos humanos ante los operadores jurídicos, tales como la interpretación conforme a la Constitución, el principio pro persona, la garantía de previa audiencia en materia de extranjeros y el desplazamiento de la facultad de investigación (antes asignada a la Corte) a la Comisión Nacional de los Derechos Humanos, entre otras. Sin embargo, este catálogo de cambios no es funcional en tanto no se precise un concepto más o menos definido de los derechos humanos, los cuales, para su cabal cumplimiento, no deben constituirse en un apartado etéreo y superficial, ya que para un país con profundas diferencias y marcadas desigualdades como el nuestro es necesario que dichos derechos se coloquen a ras de suelo y sean los grupos minoritarios y las clases más desprotegidas los receptores finales y garantes efectivos de dicho apartado.

Como consecuencia de los cambios antes referidos, el 3 de septiembre de 2013 el Pleno de la Suprema Corte de Justicia de la Nación resolvió la contradicción de tesis $293 / 2011$, la cual tiene por objeto resolver dos cuestiones fundamentales: 1) la posición jerárquica de los tratados internacionales en materia de derechos humanos frente a la Constitución Política de los Estados Unidos Mexicanos, y 2) el valor de la jurisprudencia de la Corte Interamericana de Derechos Humanos (Corte IDH) para el derecho y las decisiones judiciales nacionales.

En relación al primer tema, la contradicción 293/2011 analizó los criterios de dos tribunales colegiados. Por un lado, el Séptimo Tribunal Colegiado en materia civil del Primer Circuito estableció que «los tratados internacionales se ubican jerárquicamente por encima de las leyes federales y en segundo plano respecto de la Constitución Federal» ${ }^{2}$,

2 [TA], 9. 'época, Pleno, SJF y su Gaceta, t. X, noviembre de 1999, p. 46, tesis P. LXXVII/99, registro núm. 192.867 . 
mientras que, por otro, el Primer Tribunal Colegiado en materias administrativa y de trabajo del Décimo Primer Circuito señaló que los «tratados internacionales, cuando los conflictos se susciten en relación con derechos humanos, deben ubicarse a nivel de la Constitución» ${ }^{3}$. Así, con la decisión surgida de la contradicción 293/2011 se delimitó el llamado bloque y control de regularidad ${ }^{4}$, conforme al cual debe analizarse la validez de todas las normas y actos de autoridad que forman parte del ordenamiento jurídico nacional.

En cuanto a la jurisprudencia constitucional, se derivan tres aspectos fundamentales que deberán ser tomados en cuenta por las y los jueces: 1) en todos los casos en que sea posible se deberá armonizar la jurisprudencia interamericana con la nacional; 2) de ser imposible dicha armonización, se deberá aplicar el criterio jurisprudencial que resulte más favorecedor para la protección de los derechos humanos, y 3 ) cuando el criterio de la Corte IDH sea derivado de un caso en el que el Estado mexicano haya sido parte, la aplicabilidad del precedente al caso concreto deberá determinarse verificando la existencia de las mismas razones que motivaron el primer pronunciamiento ${ }^{5}$. A partir de las consideraciones anteriores es menester precisar que la jurisprudencia constitucional constituye el lenguaje y metalenguaje a partir del cual se construye el Derecho en nuestro país, razón por la cual la fusión del Derecho internacional con el nacional genera un híbrido a partir del cual se construyen los derechos humanos en nuestro país y por el que el principio de dignidad también transita por una visión convencional y constitucional en cuanto a su tratamiento y aplicación final.

\section{El neoconstitucionalismo en la definición de la jurisprudencia nacional}

El modelo neoconstitucional surge de un proceso histórico que se inicia con la transformación de los ordenamientos jurídicos europeos después de la Segunda Guerra Mundial, caracterizado por el reconocimiento de que en las Constituciones contemporáneas confluyen los contenidos

3 [TA], 9. ${ }^{a}$ época, TCC, SJF y su Gaceta, t. XXXI, mayo de 2010, p. 2079, tesis XI.1o.A.T.45 K, registro núm. 164.509.

${ }_{4}$ [J], 10. ${ }^{a}$ época, Pleno, SJF y su Gaceta, Libro 5, t. I, abril de 2014, p. 202, tesis P./J. 20/2014 (10. ${ }^{a}$, registro núm. 2.006.224.

5 [J], 10. ${ }^{a}$ época, Pleno, SJF y su Gaceta, Libro 5, t. I, abril de 2014, p. 204, tesis P./J. 21/2014 (10. ${ }^{a}$, registro núm. 2.006.225. 
procedimental y sustantivo mediante la definición de reglas organizativas y metarreglas que establecen principios y valores dirigidos a vincular la legislación constitucional con la ordinaria.

A partir de ello es posible definir que la constitucionalización de un determinado sistema jurídico tiene como características: la incorporación de una Constitución rígida que incluye un apartado de derechos fundamentales, una garantía jurisdiccional de la supremacía constitucional; la fuerza vinculante de la Constitución, que no es un conjunto de normas «programáticas», sino «preceptivas»; la «sobreinterpretación» de la Constitución, ya que se le interpreta extensivamente y se deducen de ella sus principios implícitos; la aplicación directa de los normas constitucionales, que también se aplican a las relaciones entre particulares; la interpretación conforme a la Constitución de las leyes y normas inferiores, y la influencia de la Constitución en el debate político ${ }^{6}$.

De forma complementaria destaca la centralidad que los derechos fundamentales comienzan a tener en la vida jurídica y política, al ser considerados como valores que impregnan todo el ordenamiento político-jurídico del Estado, cuyo influjo se extiende a las relaciones privadas. De la Constitución considerada fundamentalmente como carta política dirigida básicamente al Parlamento se pasa a su consideración como norma jurídica suprema y de aplicación directa, dirigida fundamentalmente a los tribunales, en especial al Tribunal Constitucional. Del Estado legal de Derecho se pasa al Estado constitucional de Derecho, donde la Constitución, mucho más que la ley, se convierte en el centro de todo el sistema normativo. De la centralidad del Estado y de sus prerrogativas se da lugar a la consideración de la persona humana y sus derechos como ejes del sistema jurídico. De la soberanía del legislador se pasa a la palabra final a cargo de los jueces. En el mismo sentido, los derechos fundamentales se mantienen como normas-principio y se desarrollan como tales. Por lo anterior, las normas constitucionales, entre ellas la mexicana, son por naturaleza normas-principio, con lo cual su interpretación y ubicación conceptual suele representar una antinomia no sólo como norma-regla, sino como valor.

Así, el estudio de la Constitución mexicana como norma fundamental se ha explicado bajo la idea del neoconstitucionalismo ${ }^{7}$. Bajo este mode-

${ }^{6}$ Cfr. L. E. A. Avendaño GonzÁLEZ, La dogmática de los derechos fundamentales en el siglo XXI. Una revisión al discurso reciente a cargo de la Suprema Corte de Justicia en México, México DF, UAQ, 2014, p. 82.

7 Se habla de una nueva teoría del Derecho que viene a transformar el Estado de Derecho hacia el Estado constitucional, debido a que la Constitución viene a desempeñar un 
lo, una Constitución debe separar las funciones para ejercer el poder; reconocer y garantizar los derechos fundamentales ${ }^{8}$; encauzar las negociaciones propias del juego político; sumar e incluir las fuerzas reales de la sociedad participativa, y estructurar el principio de jerarquía normativa de la Constitución como norma de normas. También la Constitución es un esquema que permea a nivel axiológico, pues constituye una exigencia al reconocer valores en sí misma, por lo que proyecta la evolución del Derecho, llevada de la mano con la migración de la moral, a los textos jurídicos positivos ${ }^{9}$, lo cual viene a confirmar que la función integradora de la Carta Magna opera también a partir de valores. En síntesis, el texto constitucional mexicano es un híbrido entre normas-regla y normas-principio.

A las consideraciones anteriores se suma la idea de que el Derecho constituye un fenómeno complejo producto de la cultura, la práctica social, la actividad económica y la política. Él mismo es producto del lenguaje y del discurso aplicado a una realidad jurídica, en donde las interpretaciones y aplicaciones no suelen ser homogéneas.

La interpretación constitucional obliga a los juzgadores a asumir una posición en la descripción y construcción del Derecho en donde la moral crítica, los principios y la razón misma obligan a conceptuar el texto constitucional como un todo moral y, a partir de ello, moldear el Derecho en nuestro país.

Por último, es necesario precisar que, de conformidad con cada postura epistémica, el Derecho adopta una posición particular, la cual va desde un conjunto de normas que regula conductas sociales, hasta mandatos de optimización en aspiración de escala moral.

papel muy importante en los sistemas jurídicos, pues es el orden que condiciona intensamente el discurso filosófico-jurídico hasta el punto de fundar justamente esa nueva teoría, que otros denominan como «paradigma del constitucionalismo». Cfr. M. ATIENZA, El sentido del Derecho, Barcelona, Ariel, 2001, pp. 309-310.

${ }^{8}$ Resulta pertinente apuntar que la calificación de fundamentales a ciertos derechos no necesariamente corresponde a que estén constitucionalizados —en razón a que la Constitución es la norma fundamental y reglamenta las instituciones fundamentales-, sino al contrario, los derechos constitucionales son o deberían ser considerados como tales porque son fundamentales. Cfr. M. Bovero, «Tutela supranacional de los derechos fundamentales», Revista Internacional de Filosofía Política, núm. 18 (2001), p. 12.

9 Cfr. J. Habermas, «¿Cómo es posible la legitimidad por vía de legalidad?», Doxa. Cuadernos de filosofía y derecho, núm. 5 (1988), p. 43. 


\section{La moral en el Derecho constitucional}

El modelo neoconstitucional dispone que la interpretación de la Constitución se encuentra estrechamente conectada con la forma de concebirla. Es decir, la metodología interpretativa y las correspondientes exigencias interpretativas no dependen de una configuración neutra, objetiva y verdadera de la Constitución, sino más bien, y cada vez más, de «una reconstrucción peculiar por parte de los intérpretes». En el mismo sentido, dado que el Derecho del Estado constitucional está caracterizado por la supremacía de la Constitución, la voluntad política debe estar subordinada al contenido de las normas constitucionales.

La interpretación de la Constitución ha sido «rematerializada» ${ }^{10}$ a partir de la incorporación de normas sustantivas que encaminan su objeto a limitar el ejercicio del poder mediante imperativos positivos; dichas normas reciben variadas denominaciones: valores, principios, directrices o derechos fundamentales, las cuales producen un efecto de irradiación sobre el sistema jurídico.

Lo anterior destruye el modelo paleo-positivista ${ }^{11}$, dado que sencillamente esas normas sustantivas no son otra cosa que normas morales. En lugar de verter un juicio moral sobre la justicia de la norma, como anteriormente se hacía, ahora se realiza un juicio jurídico sobre la validez de la misma, dado que la moral ya no flota sobre el Derecho. Por el contrario, la moral pública, en la modernidad, impregna la Constitución de eticidad, pues constituye nada menos que el puente de unión entre el Derecho y la política democrática ${ }^{12}$; así, en nada beneficia disociar el Derecho y la moral, pues ambos encarnan expectativas de justicia al invocar a los derechos como un consenso jurídico acerca de qué es permitido hacer, más que un consenso moral de lo que debería hacerse.

${ }^{10}$ Vid. L. Prieto SAnChís, «Derecho y moral en la época del constitucionalismo jurídico», Revista Brasileira de Direito Constitucional, núm. 10 (2007), p. 67.

${ }^{11}$ Ferrajoli atribuye tal concepto al Estado legislativo de Derecho o Estado legal, que surge con el nacimiento del Estado moderno como monopolio de la producción jurídica y, por tanto, del principio de legalidad como norma de reconocimiento del Derecho válido y antes aún existente, el cual sufrió tres distintas alteraciones que dieron como resultado un triple cambio del paradigma: $a$ ) en la naturaleza y estructura del Derecho; $b$ ) en la naturaleza de la ciencia jurídica, y $c$ ) en la de la jurisdicción. Vid. L. FerRajoli, «Pasado y futuro del Estado de Derecho», en M. Carbonell, Neoconstitucionalismo(s), 3. a ed., Madrid, Trotta, 2006, p. 14.

${ }_{12}$ Cfr. C. S. Nino, Derecho, moral y política, Barcelona, Ariel, 1994, p. 387. 
Esos cambios representan una extensión de la conciencia jurídica los cuales, para su operatividad, requieren dotar de valor a las propiedades estructurales en el constitucionalismo, ya que las percepciones que le recorren se ven de manera diferente si se miran desde la perspectiva de quien tiene poder político o si se miran desde la perspectiva de quien está sometido al poder político, esto es, las vértebras que componen ese paradigma deben obtener legitimidad desde un concepto valorativo.

Por tanto, el sistema jurídico mexicano se impregna crucialmente en el hecho de que los problemas de interpretación constitucional son, en lo más profundo, problemas de principios morales ${ }^{13} \mathrm{y}$ no de hechos legales o estrategias (como el enfoque profesional sugiere). De ese modo, es comprensible que se hable de la Constitución mexicana desde una perspectiva axiológica.

Así, la Constitución mexicana contiene un sistema de valores, es decir, determinaciones normativas para ejecutar un determinado proyecto político una vez que el mismo se ha hecho norma jurídica constitucional, pues en aquel entonces la Constitución fue más una idea política que una normativa, pero al cabo de la evolución del Derecho, los alcances jurídicos de las normas desde un sentido prescriptivo han contribuido a la edificación de una construcción interpretativa que no habría sólo de reconocer y legitimar principios revolucionarios o jurisprudencia positiva constitucional como reconocimiento de validez normativa, sino una Constitución como primordial manifestación del sistema de valores.

\section{Principios y normas. Un presupuesto necesario en la construcción del principio de dignidad}

La doctrina académica ha realizado una distinción relevante entre reglas y principios. Tanto las reglas como los principios son normas. Al respecto, Dworkin ${ }^{14}$ afirma que al razonar sobre derechos y obligaciones jurídicas se echa mano de estándares que no funcionan como normas, sino que operan de manera diferente, como principios, directrices políti-

${ }_{13}$ Cfr. R. Dworkin, Los derechos en serio, Barcelona, Ariel, 2009, p. 51.

${ }_{14}$ Dworkin diferencia entre, por un lado, directriz política, que es el tipo de estándar que propone un objetivo que ha de ser alcanzado (generalmente, una mejora en algún rasgo económico, político o social de la comunidad), y, por otro, principio, que es un estándar que ha de ser observado no porque favorezca o asegure una situación económica, política o social que se considera deseable, sino porque es una exigencia de la justicia, la equidad o alguna otra dimensión de la moralidad. Vid. ibid., p. 72. 
cas y otros tipos de pautas o fuentes. Al emplear principios se ve implicada la función jurisdiccional, concretamente la interpretación. Para algunos los principios son normas constitucionales sobre derecho y sobre justicia, a diferencia de las reglas, que son meras normas legislativas.

Es claro que el ordenamiento constitucional está integrado por principios cuya pertenencia al mismo no es determinada por su producción, sino por la adecuación de su contenido moral en la imposición que generan a los operadores jurídicos, y ello trae como consecuencia la «constitucionalización del ordenamiento jurídico», pues todas las normas ordinarias resultan impregnadas por las normas constitucionales ${ }^{15}$.

Para el profesor Atienza ${ }^{16}$, los principios en sentido estricto pueden formularse como enunciados que correlacionan casos con soluciones, pero que, a diferencia de las reglas, configuran el caso de forma abierta, mientras que estas últimas lo hacen de forma cerrada. En resumen, mientras que en las reglas las propiedades que conforman el caso constituyen un caso cerrado, en los principios no hay lista de periferia menor, sino que su indeterminación requiere de ejercicios densos en la creación operativa del derecho en cuestión. Para Alexy ${ }^{17}$, los principios son mandatos de optimización que se caracterizan por ser normas que ordenan la realización de determinado fin de acuerdo a la gradación necesaria en relación a las posibilidades jurídicas y fácticas, es decir, son susceptibles de cumplirse en diferentes grados, mientras que, por otro lado, las reglas sólo pueden ser cumplidas o incumplidas.

Así, los principios despliegan sus efectos a lo largo de todo el ordenamiento jurídico, conduciendo una eficacia horizontal frente al poder, y, por tanto, adquieren mayor jerarquía en el interior del ordenamiento jurídico. Por ejemplo, los derechos fundamentales contenidos en el texto constitucional son principios en sentido cualitativo o sustancial, pues mediante éstos se defienden y legitiman los asuntos fundamentales para la comunidad que regula.

Las reglas jurídicas constituyen razones protegidas, pues ordenan realizar una acción exigida y, a su vez, excluyen o suprimen cualquier delibe-

15 Vid. R. Guastini, «La constitucionalización del ordenamiento jurídico: el caso italiano», en M. Carbonell (coord.), Neoconstitucionalismo(s), 3. ${ }^{a}$ ed., Madrid, Trotta, 2006, pp. 49 y 50.

${ }^{16}$ Cfr. M. Atienza y J. Ruiz Manero, «Sobre principios y reglas», Doxa. Cuadernos de filosofía y derecho, núm. 10 (1991), p. 108.

17 Cfr. C. Bernal Pulido, Epílogo a la teoría de los derechos fundamentales, en traducción a R. Alexy, Madrid, Colegio de Registradores de la Propiedad, Mercantiles y Bienes Muebles de España, 2004, p. 13. 
ración por parte de su destinatario respecto al cumplimiento o no de la acción ordenada; de ese modo las reglas están destinadas a que, cuando se den sus condiciones de aplicación, los órganos jurisdiccionales excluyan, en la base de su resolución, su propio juicio acerca del balance de razones aplicables y adopten como tal base el contenido de la regla, lo cual implica que los principios doten de sentido al derecho, incluyendo la sistematización de las reglas que lo confronten. La polémica salta cuando entre principios habrá de racionalizarse el derecho mediante el método de la ponderación, pues contienen en sí una mayor fuerza expansiva de alcance justificable concreto; empero, ¿qué sucede al identificar contradicciones encerradas en el texto constitucional, avaladas como válidas precisamente por su ubicación normativa, y que sugieren igualmente una refutación obligada al evolucionado paradigma del neoconstitucionalismo, abriendo brecha a un choque contra el sistema constitucional de valores, ya que simplemente no pueden oponerse dos directrices indeterminadas que marcan un punto de partida?

De modo que el punto toral para la distinción entre reglas y principios es que estos últimos son normas que ordenan que se realice algo en la mayor medida posible en relación con las posibilidades jurídicas y fácticas, es decir, en sistema de gradación, y, por su parte, las reglas son normas que simplemente exigen su cumplimiento, y en esa medida pueden o no ser cumplidas.

Ahora bien, es imposible crear una lista completa de los principios de un sistema jurídico, pues inclusive no hay determinación sobre el valor superior entre principios, es decir, no hay relación de prioridad entre ellos, ya que su gradación no depende de la preferencia en sí, sino del resultado mismo en el caso concreto (aquella Constitución que incorpore los seis principios elementales: dignidad humana, libertad, igualdad, democracia, Estado de Derecho y Estado social, establece un sistema jurídico racional). Aun con ello, lo cierto es que no es posible establecer un orden que conduzca en cada caso a un resultado, orden que se consideraría estricto; dicha medición de intensidad o peso del principio tiene su expresión calculable hasta en tanto su colisión se resuelva mediante la ponderación; así, las condiciones de prioridad se establecen hasta la decisión de esa confrontación, bajo una inclusiva participación de la teoría de la argumentación jurídica al momento de decidir, lo que supone reflexiones de contenido moral, pues la cuestión finalmente trata de fundamentar adecuadamente los juicios prácticos y morales insertos en el paradigma constitucional. 
En síntesis, es posible afirmar que no hay un criterio universal de ética o de justicia; los principios éticos actuales se formulan como derechos humanos, y a partir de ello se crean nuevas formas de convivencia moral.

\section{EL PRINCIPIO DE DIGNIDAD EN LA JURISPRUDENCIA CONSTITUCIONAL MEXICANA}

El trato digno implica un trato respetuoso. La dignidad humana para estar presente no amerita necesariamente palabras, sino actitudes de reconocimiento. En términos de Becchi, el concepto de dignidad humana puede circunscribirse a dos ideas generales: por un lado, dignidad indica la posición especial del hombre en el cosmos; por el otro, la posición que ocupa en la vida pública ${ }^{18}$. A partir de ello, la idea general de la dignidad ontológica pertenece y es la misma para todos; de igual forma es única, ya que representa un valor residente en el solo hecho de existir; por ello, todo hombre, cualquiera que sea su condición, es digno. Al suponer lo contrario, la visión del ser humano se limitaría a un hecho biológico y social.

El origen y fundamento de los derechos fundamentales descansa en el concepto de la «dignidad humana». La dignidad humana no sólo doctrinal, sino jurisprudencial, es un medio para modular y, en su caso, condicionar la interpretación, ejercicio y aplicación de los derechos humanos. La misma también constituye el rasgo distintivo de los seres humanos respecto a los seres vivos, la que constituye a la persona como un fin en sí mismo, impidiendo que sea considerada como un instrumento o medio para otro fin, además de dotarlo de capacidad de autodeterminación y de realización del libre desarrollo de la personalidad.

Las consideraciones anteriores obligan a deducir la naturaleza de los derechos humanos a partir de la jurisprudencia nacional. La jurisprudencia puede ser objeto de estudio desde dos posiciones: la positivista, que define los derechos como aquellos que el Estado otorga en un orden jurídico determinado, y la naturalista, que los define como aquellos que el Estado reconoce y garantiza en alguna medida. En cuanto a conceptos jurídicos, en el positivismo se expresa que es el orden jurídico el que otorga la calidad de persona al ser humano, es decir, persona es una categoría jurídica que se puede conceder o no, o de la cual se puede excluir a un ser humano o a un grupo de ellos, como pueden ser los esclavos, los extranjeros, la mujeres, etc.

18 P. BeCCH, El principio de dignidad humana, México DF, Fontamara, 2014, p. 11. 
En cambio, en las concepciones de derecho natural, el ser humano, por el solo hecho de existir, es persona y posee derechos y obligaciones. El Estado no puede desconocer esa situación, lo único que realiza es el reconocimiento de este hecho y, a partir de él, garantiza diversas series de derechos ${ }^{19}$.

De las consideraciones anteriores podríamos sintetizar que la naturaleza de un derecho humano, a partir del discurso jurisprudencial, debe ser definida como aquella exigencia ética de importancia fundamental que se adscribe a toda persona humana, sin excepción, por razón de esa sola condición. Exigencia sustentada en valores o principios que se han traducido históricamente en normas de Derecho nacional e internacional en cuanto parámetro de justicia y legitimidad política.

A lo anterior es necesario agregar que, por una parte, la noción de dignidad humana es lo que singulariza a la persona respecto a otros seres vivos debido a su razón, voluntad, libertad, igualdad e historicidad, y, por otra, los derechos humanos son por sí mismos el conjunto de atribuciones reconocidas por instrumentos jurídicos para hacer efectiva la idea de dignidad de todas las personas. Ambas circunstancias permiten una existencia humana desde diversos ámbitos relacionados entre sí, como son el individual, social, político, económico y cultural.

\section{El derecho al mínimo vital en la jurisprudencia constitucional}

A partir de las consideraciones anteriores, el Derecho mexicano moduló su jurisprudencia para que reflejara el sentido de dignidad a través de un mínimo vital. Así, en términos de la jurisprudencia emitida por el Pleno de la Suprema Corte de Justicia con el título «Derecho al mínimo vital. Su contenido trasciende a todos los ámbitos que prevean medidas estatales que permitan respetar la dignidad humana», se dispone que:

«También reconoce que el derecho al mínimo vital trasciende tanto a la materia fiscal como a la laboral, y abarca un conjunto de medidas estatales de diversa índole (acciones positivas y negativas) que permiten respetar la dignidad humana en las condiciones prescritas por el art. 25 constitucional, tomando en cuenta que ese derecho no sólo se refiere a un mínimo para la supervivencia económica, sino también para la existencia libre y digna descrita en la parte dogmática de la Constitución Federal, lo cual, en términos de su art. $1^{\circ}$, , resulta concordante con los instrumentos inter-

\footnotetext{
19 bttp://www.juridicas.unam.mx/publica/librev/rev/cconst/cont/25/ard/ard1.pdf.
} 
nacionales que son fundamento de los derechos humanos reconocidos por la Ley Suprema» ${ }^{20}$.

De las consideraciones anteriores es necesario especificar que el «derecho al mínimo vital» no se circunscribe a lo tributario y se proyecta sobre la necesidad de que el Estado garantice la disponibilidad de ciertas prestaciones en materia de procura existencial o asistencia vital, a partir del cual éste deberá asumir la tarea de remover los obstáculos de orden económico y social que impidan el pleno desarrollo de la persona y la efectiva participación de todos los ciudadanos en la organización política, económica, cultural y social del país.

\section{El concepto de dignidad en la jurisprudencia constitucional mexicana}

En primer lugar, la metodología empleada para la localización de la jurisprudencia constitucional se circunscribe a la búsqueda de la 9. ${ }^{a}$ y $10 .{ }^{a}$ época, y, en segundo lugar, se hace un llamado de la voz «dignidad». Por cuestión de orden y método se identifican en primer lugar los títulos que pertenecen a la 9. ${ }^{a}$ época en materia de criterios jurisprudenciales:

a) En términos de la jurisprudencia emitida por la Primera Sala de la Suprema Corte de Justicia, bajo el título «Dignidad humana. El orden jurídico mexicano la reconoce como condición y base de los demás derechos fundamentales», se dispone que: «El art. 1. ${ }^{\circ}$ de la Constitución Política de los Estados Unidos Mexicanos establece que todas las personas son iguales ante la ley, sin que pueda prevalecer discriminación alguna por razones étnicas o de nacionalidad, raza, sexo, religión o cualquier otra condición o circunstancia personal o social que atente contra la dignidad humana y que, junto con los instrumentos internacionales en materia de derechos humanos suscritos por México, reconocen el valor superior de la dignidad humana, es decir, que en el ser humano hay una dignidad que debe ser respetada en todo caso, constituyéndose como un derecho absolutamente fundamental, base y condición de todos los demás, el derecho a ser reconocido y a vivir en y con la dignidad de la persona humana, y del cual se desprenden todos los demás derechos, en cuanto son necesarios para que

20 [TA], 10. ${ }^{a}$ época, Pleno, SJF y su Gaceta, Libro 1, t. I, diciembre de 2013, p. 136, tesis P. VII/2013 $\left(9 .^{a}\right)$, registro núm. 159.820. 
los individuos desarrollen integralmente su personalidad, dentro de los que se encuentran, entre otros, el derecho a la vida, a la integridad física y psíquica, al honor, a la privacidad, al nombre, a la propia imagen, al libre desarrollo de la personalidad, al estado civil y el propio derecho a la dignidad personal» ${ }^{21}$.

b) En términos de la jurisprudencia emitida por los Tribunales Colegiados de Circuito, bajo el título «Militares. El retiro del activo por detección del VIH y la consecuente cesación de los servicios médicos, extensiva a sus familiares contagiados, debe resolverse conforme al marco regulatorio de los derechos a la no discriminación y a la dignidad de las personas, a la salud, a la permanencia en el empleo y a de los derechos de los niños», se dispone que: «Se declarará la procedencia del retiro del activo de un militar por quedar inutilizado en actos fuera del servicio. Ahora bien, tales disposiciones son insuficientes para declarar el retiro del militar, positivo a las pruebas del virus de inmunodeficiencia humana $(\mathrm{VIH})$, y la consecuente cesación de los servicios médicos que se le venían proporcionando, extensiva a sus familiares derechohabientes contagiados por el virus, en virtud de que existe un marco regulatorio más amplio que, con base en una interpretación sistemática, causal teleológica y por principios, debe considerarse en aras de una mayor protección de los derechos fundamentales y de la dignidad de las personas» ${ }^{22}$.

c) En términos de la jurisprudencia emitida por el Pleno de la Suprema Corte de Justicia de la Nación, bajo el título «Salud. El derecho a su protección, que como garantía individual consagra el art. $4 .^{\circ}$ constitucional, comprende la recepción de medicamentos básicos para el tratamiento de las enfermedades y su suministro por las dependencias y entidades que prestan los servicios respectivos», se dispone que: «Por servicios de salud se entienden las acciones dirigidas a proteger, promover y restaurar la salud de la persona y de la colectividad; que los servicios de salud se clasifican en tres tipos: de atención médica, de salud pública y de asistencia social; que son servicios básicos de salud, entre otros, los consistentes en: a) la atención médica, que comprende actividades preventivas, curativas y de rehabilitación, incluyendo la atención de urgencias, definiéndose a las actividades curativas como aquellas que tienen como fin efectuar un diagnóstico temprano y proporcionar tratamiento oportuno, y $b$ ) la disponibilidad

${ }^{21}$ [TA], 9. ${ }^{a}$ época, Pleno, SJF y su Gaceta, t. XXX, diciembre de 2009, p. 8, tesis P. LXV/2009, registro núm. 165.813.

22 [TA], 9. ${ }^{a}$ época, TCC, SJF y su Gaceta, t. XX, octubre de 2004, p. 2363, tesis I.4o.A.438 A, registro núm. 180.322. 
de medicamentos y otros insumos esenciales para la salud, para cuyo efecto habrá un cuadro básico de insumos del sector salud. Deriva de lo anterior, que se encuentra reconocido en la Ley General de Salud, reglamentaria del derecho a la protección de la salud, el que tal garantía comprende la recepción de los medicamentos básicos para el tratamiento de una enfermedad como parte integrante del servicio básico de salud consistente en la atención médica, que en su actividad curativa significa el proporcionar un tratamiento oportuno al enfermo, lo que incluye, desde luego, la aplicación de los medicamentos básicos correspondientes conforme al cuadro básico de insumos del sector salud, sin que obste a lo anterior el que los medicamentos sean recientemente descubiertos y que existan otras enfermedades que merezcan igual o mayor atención por parte del sector salud, pues éstas son cuestiones ajenas al derecho del individuo de recibir los medicamentos básicos para el tratamiento de su enfermedad, como parte integrante del derecho a la protección de la salud que se encuentra consagrado como garantía individual, y del deber de proporcionarlos por parte de las dependencias y entidades que prestan los servicios respectivos» ${ }^{23}$.

d) En términos de la tesis aislada emitida por el Pleno de la Suprema Corte de Justicia de la Nación, bajo el título «Matrimonio entre personas del mismo sexo. La reforma al art. 146 del Código Civil para el Distrito Federal, publicada en la Gaceta Oficial de la entidad el 29 de diciembre de 2009, no contraviene el contenido de la Constitución Política de los Estados Unidos Mexicanos», se dispone que: «La orientación sexual de una persona, como parte de su identidad personal, responde a un elemento relevante en su proyecto de vida que incluye el deseo de tener una vida en común con otra persona de igual o distinto sexo, por lo que tratándose de personas homosexuales, de la misma forma que ocurre con las heterosexuales, el derecho al libre desarrollo de la personalidad implica también el de decidir casarse o no. En tal sentido, en respeto a la dignidad humana resulta exigible el reconocimiento por parte del Estado no sólo de la orientación sexual de un individuo hacia personas de su mismo sexo, sino también de sus uniones bajo las modalidades que, en un momento dado, decida adoptar (sociedades de convivencia, pactos de solidaridad, concubinatos o matrimonio), razón por la cual la decisión tomada por la Asamblea Legislativa del Distrito Federal para ampliar la institución del matrimonio y comprender a las parejas del mismo sexo, lejos de contravenir los

${ }^{23}$ [TA], 9. 'época, Pleno, SJF y su Gaceta, t. XI, marzo de 2000, p. 112, tesis P. XIX/2000, registro núm. 192.160. 
postulados fundamentales, los refuerza, al igualar las uniones de las parejas, sean heterosexuales $u$ homosexuales» ${ }^{24}$.

En síntesis, la 9. época arrojó cuatro criterios que identifican el concepto «dignidad» o «dignidad humana»; los criterios jurisprudenciales vertidos hasta entonces comprenden los años de 1994 a 2011, es decir, previo a la reforma constitucional del 10 y 11 de junio de 2011.

Por cuestión de orden y método se identifican ahora los criterios que pertenecen a la 10. época:

a) La Corte, bajo bajo el título «Dignidad humana. Definición» ${ }^{25}$, se ha pronunciado respecto a que «la dignidad humana es el origen, la esencia y el fin de todos los derechos humanos». En el mismo sentido, bajo el título «Dignidad humana. Su naturaleza y concepto», ha expresado que constituye «un valor supremo, en virtud del cual se reconoce una calidad única y excepcional a todo ser humano por el simple hecho de serlo, cuya plena eficacia debe ser respetada y protegida integralmente sin excepción» ${ }^{26}$.

b) En términos de la tesis aislada emitida por la Primera Sala de la Suprema Corte de Justicia de la Nación, bajo el título «Dignidad humana. Constituye una norma jurídica que consagra un derecho fundamental a favor de las personas y no una simple declaración ética», se dispone que: «La dignidad humana no es una simple declaración ética, sino que se trata de una norma jurídica que consagra un derecho fundamental a favor de la persona y por el cual se establece el mandato constitucional a todas las autoridades, e incluso particulares, de respetar y proteger la dignidad de todo individuo, entendida ésta como el interés inherente a toda persona, por el mero hecho de serlo, a ser tratada como tal y no como un objeto, a no ser humillada, degradada, envilecida o cosificada ${ }^{27}$.

c) En términos de la tesis aislada emitida por la Primera Sala de la Suprema Corte de Justicia de la Nación, bajo el título «Igualdad y no discriminación por cuestiones de género. Para analizar si una ley cumple con este derecho fundamental debe tenerse en cuenta que la discriminación puede ser directa e indirecta», se dispone que: «Para analizar si una ley

24 [TA], 9. ${ }^{a}$ época, Pleno, SJF y su Gaceta, t. XXXIV, agosto de 2011, p. 877, tesis P. XXVIII/2011, registro núm. 161.268.

${ }^{25}$ [J], 10. ${ }^{a}$ época, TCC, SJF y su Gaceta, Libro I, t. 3, octubre de 2011, p. 1528, tesis I.5o.C. J/30 (9. $\left.{ }^{a}\right)$, registro núm. 160.870.

${ }^{26}$ [J], 10. ${ }^{a}$ época, TCC, SJF y su Gaceta, Libro I, t. 3, octubre de 2011, p. 1529, tesis I.5o.C. J/31 $\left(9{ }^{a}\right)$, registro núm. 160.869.

27 [TA], 10. ${ }^{a}$ época, 1. ${ }^{a}$ Sala, SJF y su Gaceta, Libro 11, t. I, octubre de 2014, p. 602, tesis 1. ${ }^{a}$ CCCLIV/2014 (10. $\left.{ }^{a}\right)$, registro núm. 2.007.731. 
ordinaria cumple o no con el derecho humano a la igualdad y no discriminación por cuestiones de género, reconocido en el art. 1. ${ }^{\circ}$ de la Constitución Política de los Estados Unidos Mexicanos, el cual se robustece con el numeral $4 .^{\circ}$, párrafo primero, de la propia Constitución, debe considerarse que dicha discriminación puede ser directa e indirecta. La directa se presenta cuando la ley da a las personas un trato diferenciado ilegítimo, mientras que la indirecta se actualiza cuando la discriminación se genera como resultado de leyes, políticas o prácticas que, en apariencia, son neutrales, pero que impactan adversamente en el ejercicio de los derechos de ciertos grupos o personas» ${ }^{28}$.

d) En términos de la jurisprudencia emitida por los Tribunales Colegiados de Circuito, bajo el título «Derecho a la dignidad humana. Es connatural a las personas físicas y no a las morales», se dispone que: «Con la reforma al art. $1 .^{\circ}$ de la Constitución Política de los Estados Unidos Mexicanos, publicada en el Diario Oficial de la Federación el 10 de junio de 2011, se advierte que la intención del constituyente permanente de sustituir en su primer párrafo la voz "individuo" por "personas" es la de utilizar una expresión que no se refiera a un género en particular y abarcar "a todo ser humano titular de iguales derechos y deberes emanados de su común dignidad, y en los casos en que ello sea aplicable debe ampliarse a las personas jurídicas" ${ }^{29}$.

e) En términos de la tesis aislada emitida por la Primera Sala, bajo el título «Igualdad y no discriminación. Notas relevantes que el operador de la norma debe considerar al examinar la constitucionalidad de una medida a la luz de dichos principios, frente a las llamadas "categorías sospechosas", a fin de no provocar un trato diferenciado o una discriminación institucional», se dispone que: «Esta Primera Sala de la Suprema Corte de Justicia de la Nación ha establecido que las distinciones basadas en alguno de los criterios enunciados en el último párrafo del art. $1 .^{\circ}$ constitucional, también conocidas como "categorías sospechosas" (el origen étnico o nacional, el género, la edad, las discapacidades, la condición social, las condiciones de salud, la religión, las opiniones, las preferencias sexuales, el estado civil o cualquier otra que atente contra la dignidad humana y tenga por objeto anular o menoscabar los derechos y libertades de las personas), requieren que el operador de la norma realice un escrutinio estric-

28 [TA], 10. ${ }^{a}$ época, 1. ${ }^{a}$ Sala, SJF y su Gaceta, Libro 10, t. I, septiembre de 2014, p. 579, tesis $1{ }^{a}{ }^{a}$ CCCVI/2014 (10. $\left.{ }^{a}\right)$, registro núm. 2.007.338.

${ }_{29}[J], 10{ }^{a}$ época, TCC, SJF y su Gaceta, Libro XXIII, t. 3, agosto de 2013, p. 1408, tesis VI.3o.A. J/4 (10. $\left.{ }^{a}\right)$, registro núm. 2.004.199. 
to de la medida para examinar su constitucionalidad a la luz del principio de igualdad. $\mathrm{Al}$ respecto, es de señalar que tanto la Constitución como los tratados internacionales en materia de derechos humanos suscritos por el Estado Mexicano prevén la posibilidad de otorgar un trato desigual a quienes no se encuentran en una paridad frente a los otros sujetos, si dicho trato implica una distinción justificada; pero si, por el contrario, la medida adoptada carece de razonabilidad, entonces será excluyente y, por ende, discriminatoria. Esto es, si bien la igualdad de trato implica la eliminación de distinciones o exclusiones arbitrarias prohibidas por la Constitución, lo cierto es que determinadas distinciones pueden ser favorecedoras y encontrarse justificadas, como ocurre con las acciones positivas, que buscan dar preferencia a sectores históricamente marginados y vulnerables para compensar las desventajas que sufren» ${ }^{30}$.

f) En términos de la tesis aislada emitida por la Primera Sala, bajo el título «Dignidad humana. Constituye una norma jurídica que consagra un derecho fundamental a favor de las personas y no una simple declaración ética», se dispone que: «La dignidad humana no se identifica ni se confunde con un precepto meramente moral, sino que se proyecta en nuestro ordenamiento como un bien jurídico circunstancial al ser humano, merecedor de la más amplia protección jurídica, reconocido actualmente en los arts. $1 .^{\circ}$, último párrafo; $2 .^{\circ}$, apartado A), fracción II; $3 .^{\circ}$, fracción II, inciso c), y 25 de la Constitución Política de los Estados Unidos Mexicanos. En efecto, el Pleno de esta Suprema Corte ha sostenido que la dignidad humana funge como un principio jurídico que permea en todo el ordenamiento, pero también como un derecho fundamental que debe ser respetado en todo caso, cuya importancia resalta al ser la base y condición para el disfrute de los demás derechos y el desarrollo integral de la personalidad. Así las cosas, la dignidad humana no es una simple declaración ética, sino que se trata de una norma jurídica que consagra un derecho fundamental a favor de la persona y por el cual se establece el mandato constitucional a todas las autoridades, e incluso particulares, de respetar y proteger la dignidad de todo individuo, entendida ésta —en su núcleo más esencial— como el interés inherente a toda persona, por el mero hecho de serlo, a ser tratada como tal y no como un objeto, a no ser humillada, degradada, envilecida o cosifica» ${ }^{31}$.

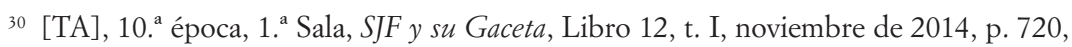
tesis $1 .{ }^{a}$ CCCLXXXIV/2014 $\left(10{ }^{a}{ }^{a}\right)$, registro núm. 2.007.924.

31 [TA], 10. ${ }^{a}$ época, 1. a Sala, SJF y su Gaceta, Libro 11, t. I, octubre de 2014, p. 602, tesis 1. ${ }^{a}$ CCCLIV/2014 (10. $\left.{ }^{a}\right)$, registro núm. 2.007.731. 
g) En términos de la tesis aislada emitida por el Tribunal Colegiado de Circuito, bajo el título «Instituto de Seguridad Social del Estado de México y Municipios. La verificación de la dependencia económica del posible beneficiario de sus servicios, mediante el estudio socioeconómico que se le practique conforme al formato aprobado por el comité de afiliación, al permitir la invasión de espacios de su vida privada, viola el derecho fundamental a la dignidad humana», se dispone que «el estudio socioeconómico que se practique se realizará conforme al formato aprobado por el comité de afiliación, el cual contendrá datos generales del solicitante y posibles beneficiarios, descripción del núcleo familiar, ingresos y egresos de éste, así como información relevante para ese fin» ${ }^{32}$.

b) En términos de la tesis aislada emitida por los Tribunales Colegiados de Circuito, bajo el título «Divorcio necesario. Debe decretarse, aun cuando no queden demostradas las causales invocadas, tomando en consideración el derecho fundamental a la dignidad humana», se dispone que: «De la dignidad humana, como derecho fundamental superior, deriva el libre desarrollo de la personalidad, que comprende, entre otras expresiones, la libertad de contraer matrimonio o no hacerlo; de procrear hijos y cuántos, o bien decidir no tenerlos; de escoger su apariencia personal, su profesión o actividad laboral, así como la libre opción sexual, en tanto que todos estos aspectos son parte de la forma en que una persona desea proyectarse y vivir su vida, y que, por tanto, sólo a ella corresponde decidir autónomamente. Por tanto, no obstante que no quede demostrada la causal de divorcio invocada por uno de los cónyuges, o ambos en caso de reconvención, la autoridad que conozca del juicio debe advertir que ya no existe la voluntad de al menos una de las partes para seguir unida en matrimonio y debe tenerla en cuenta para determinar lo que mejor les conviene, tomando en consideración su derecho fundamental a la dignidad humana y, en esa medida, decretar el divorcio [...] En consecuencia, para decretar el divorcio, el juez natural debe atender que: a) lo solicite uno o ambos consortes; $b$ ) por el tiempo transcurrido de convivencia se evidencie que éste fue suficiente para que ya se hubiera logrado una reconciliación y no se obtuvo, y c) las circunstancias particulares pongan de manifiesto que la relación ya provocó o está provocando un perjuicio a la estabilidad personal o familiar, según sea el caso» ${ }^{33}$.

32 [TA], 10. ápoca, TCC, SJF y su Gaceta, Libro 6, t. III, mayo de 2014, p. 2038, tesis II.1o.A.14 A (10. $\left.{ }^{a}\right)$, registro núm. 2.006.575.

33 [TA], 10. ápoca, TCC, SJF y su Gaceta, Libro 2, t. IV, enero de 2014, p. 3051, tesis XVIII.4o.15 C (10. $\left.{ }^{a}\right)$, registro núm. 2.005.339. 
i) En términos de la jurisprudencia emitida por el Pleno de la Corte, bajo el título «Trabajo penitenciario. Su desarrollo debe estar erigido sobre la observancia y el respeto a la dignidad humana», se dispone que: «El principio de la dignidad humana contenido en el último párrafo del art. $1 .{ }^{\circ}$ de la Constitución Política de los Estados Unidos Mexicanos funge como una herramienta fundamental que contribuye a la hermenéutica constitucional, cuya importancia radica en que define la condición del ser humano en cuanto a entidad ontológica y jurídica, caracterizada por entrever condiciones que le son inherentes, de forma que lo que comporta la categoría de persona humana delimita lo que ha de entenderse por dignidad humana. Así pues, el trabajo penitenciario, que debe ser visto como un deber-derecho y no como una actividad forzosa, tiene como principio rector la reinserción social, erigida a su vez sobre la observancia y el respeto al principio de la dignidad humana, al ser condición y base de los demás derechos» ${ }^{34}$.

En síntesis, la 10. época arrojó diez criterios que identifican el concepto «dignidad» o «dignidad humana»; los criterios jurisprudenciales vertidos hasta entonces comprenden los años de 2011 a la fecha, es decir, posterior a la reforma constitucional de 10 y 11 de junio de 2011 .

\section{CONCLUSIONES}

La jurisprudencia constitucional a cargo del poder judicial federal a partir de la reforma constitucional de 10 y 11 de junio de 2011 incorporó el principio de dignidad humana como presupuesto sine qua non en la definición, tratamiento e interpretación del Derecho mexicano.

Lo anterior permite positivar, tomando como referencia el marco nacional e internacional, un concepto fundamental a partir del cual se construyen los derechos humanos. En el mismo sentido, permite distinguir que la Constitución misma constituye un esquema infiltrado a nivel axiológico, lo cual exige reconocer valores en sí misma.

En síntesis, el binomio dignidad-jurisprudencia permite distinguir la migración de la moral a los textos jurídicos positivos, lo cual viene a demostrar que la función integradora de la Carta Magna opera también a partir de valores. Como consecuencia, el texto constitucional mexicano es un híbrido normas-regla y normas principio.

${ }^{34}$ Localización: [J]; 10. ápoca, Pleno, S. J. F. y su Gaceta, Libro 1, diciembre de 2013, t. I, p. 128. P./J. 34/2013 (10.), registro núm. 2005110. 
Por tanto, el sistema jurídico mexicano se impregna crucialmente en el hecho de que los problemas de interpretación constitucional son también problemas de principios morales. De ese modo, es comprensible que se hable de la Constitución mexicana desde una perspectiva axiológica. Es decir, los problemas de interpretación constitucional son problemas de principios morales.

\section{BIBLIOGRAFÍA}

Atienza, M., El sentido del Derecho, Barcelona, Ariel, 2001.

Atienza, M., y Ruiz Manero, J., «Sobre principios y reglas», Doxa. Cuadernos de filosofía y derecho, núm. 10 (1991), pp. 101-120.

Avendaño GonzÁlez, L. E. A., La dogmática de los derechos fundamentales en el siglo XXI. Una revisión al discurso a cargo de la SCJN, México DF, UAQ, 2014.

BECCHI, P., El principio de la dignidad humana, México DF, Fontamara, 2012.

Bernal Pulido, C., Epílogo a la teoría de los derechos fundamentales, en traducción a R. Alexy, Madrid, Colegio de Registradores de la Propiedad, Mercantiles y Bienes Muebles de España, 2004.

Bovero, M., «Tutela supranacional de los derechos fundamentales», Revista internacional de filosofía política, núm. 18 (2001), pp. 5-24.

Dworkin, R., Los derechos en serio, Madrid, Ariel, 2009.

Habermas, J., «¿Cómo es posible la legitimidad por vía de legalidad?», Doxa. Cuadernos de filosofía y derecho, núm. 5 (1988), pp. 21-46.

GUASTINI, R., «La constitucionalización del ordenamiento jurídico: el caso italiano», en M. Carbonell, Neoconstitucionalismo(s), 3. ${ }^{a}$ ed., Madrid, Trotta, 2006.

Nino, C. S., Derecho, moral y política, Barcelona, Ariel, 1994.

Prieto Sanchís, L., «Derecho y moral en la época del constitucionalismo jurídico», Revista Brasileira de Direito Constitucional, núm. 10 (2007), pp. 68 y ss.

TAMAYO y SALMORÁN, R., Razonamiento y argumentación jurídica. El paradigma de la racionalidad y la ciencia del derecho, México DF, UNAM, 2014, disponible en bttp://www.juridicas.unam.mx/publica/librev/rev/cconst/cont/25/ard/ard1.pdf. 